\title{
Tenth year of Headache Medicine Journal, 25 years of Brazilian publications in the headache field
}

It is surprising to look back and realize that Headache Medicine, the Journal of the Brazilian Headache Society, is now in its tenth year. Not only that, but also the fact that the Brazilian Headache Society through our journals, Headache Medicine, formerly known as "Migraneas \& Cefaleias", has been publishing scientific articles since 1994. This attests to the Brazilian tradition in the field.

Nonetheless, we now live in a new era of online journals, completely different submission processes, alternative metrics to academic scientific citations, so it is high time to put our Journal and the supportive Brazilian Headache Society in its deserved place among outstanding international journals in the field of Neurology. It is time for us to become truly International, to be part of all main indexation databases. We have grown up and are gradually moving in this direction.

The editorial board has been renewed, with the exceptional cooperation of outstanding researchers from the United States, Asia, Europa and Latin America.

Mario Peres has joined Marcelo Valença as joint editor-in-chief, and a new board of associate editors has been selected to cover different areas in headache science, such as, Procedures, Women and headaches, Clinical trials, Orofacial pain, Theses, Non-pharmacological treatments, Secondary headaches, Intracranial hypotension and hypertension, Trigemino-autonomic cephalgias and Headaches in children.

A number of new sections have been introduced including controversies, expert opinions, images and video, and advocacy. Professor Wilson Luiz Sanvito, our editor emeritus, will contribute with his thoughtful articles, and Professor Silva-Neto, the scientific editor, the liaison member with the editorial board and the editors-in-chief. The contributions of previous editors need to be duly recognized for, we would not be around today without their invaluable efforts.

We hope everyone contributing to Headache Medicine will never regret it. We trust that all the studies or articles already published or due to appear in forthcoming editions will make us proud to be part of this dynamic scientific community.

Our journal Headache Medicine and the Brazilian Headache Society have been recognized by the American Headache Society and its outstanding journal Headache (The Journal of Head and Face Pain). A new supplement on Brazilian Headache Medicine is on course to be launched soon, similar to previous ones in 2007 and $2015 .{ }^{12}$ A virtual section has been added to the Headache Journal website on Brazilian headache medicine since $2012 .{ }^{3}$ Also, Toolboxes, translated to Brazilian Portuguese, ${ }^{4}$ can be found on this website, a section dedicated to patient education on a specific topic, a clear indication of the prestige in which our society is held. This indicates that our work and prestige as headache specialists have been recognized, as have our efforts in contributing to the progress of Headache Medicine worldwide.

Mario Fernando Prieto Peres Marcelo Moraes Valença

Editors-in-Chief, Headache Medicine

\section{REFERENCES}

1. Valença MM. The Brazilian contribution to the diagnosis and treatment of headache disorders. Headache. 2015 Feb;55 Suppl 1:1-3.

2. Valença MM, da Silva AA, Bordini CA. Headache research and medical practice in Brazil: an historical overview. Headache. 2015 Feb;55 Suppl 1:4-31.

3. https://headachejournal.onlinelibrary.wiley.com/doi/toc/10.1111/(ISSN)1526-4610.cefaliatria_no_brasil

4. https://headachejournal.onlinelibrary.wiley.com/page/journal/15264610/homepage/material_educativo_sobre_cefaleia_dor_ de_cabea_htm 